\title{
Properties of Cocoyam Starch as Binders in Ibuprofen Tablets
}

\author{
Judith Chitedze-Kumatso*, Davies Emmanuel Mweta \\ Malawi University of Science and Technology, P.O. Box 5196, Limbe, Malawi. \\ *Corresponding author's E-mail: jckumatso@must.ac.mw
}

Received: 18-05-2020; Revised: 14-08-2020; Accepted: 21-08-2020.

DOI: $10.47583 /$ ijpsrr.2020.v64i01.003

\section{ABSTRACT}

The study was undertaken to evaluate the suitability of native cocoyam starches as binders in ibuprofen tablet formulations. The starches were used as binders for $400 \mathrm{mg}$ ibuprofen tablets produced by wet granulation at various concentrations $(2,4,6$ and $8 \%$ $\mathrm{w} / \mathrm{w}$ ) and compressed at different punch settings (23-27 Pa). The produced tablets were evaluated for weight uniformity, hardness, friability and disintegration against corn starch tablets. The best operating conditions for the produced tablets were the punch setting of $24 \mathrm{~Pa}$ and binder concentration of $2 \% \mathrm{w} / \mathrm{w}$. Mzuzu cocoyam starch was found to be the most appropriate binder. Malaw needs therefore to exploit cocoyam starch in tablet formulations.

Keywords: starch, ibuprofen, binder, tablet, cocoyam starch.

\section{INTRODUCTION}

tarch, a polysaccharide obtained from roots, stems, tubers, fruits and seeds is used as an excipient in the pharmaceutical industry. ${ }^{1,2}$ Corn starch is the most utilized Excipient in the pharmaceutical industry while corn is a staple crop for most people in sub-Saharan Africa including Malawi. ${ }^{3,4}$ Most industries in Malawi use corn starch for tablet formation. ${ }^{5}$ Increased food demands in the sub-Saharan Africa have necessitated the search for alternatives and starchy root crop like cocoyam (Colocasia esculenta) is a potential raw material. All the starches that are used in the Malawian industries are imported from South Africa, Zimbabwe, Tanzania, United Arab Emirates, China, India, Kenya and United Kingdom constituting corn, potato and wheat. 6,7 The importation of starch has lead to loss of foreign currency and increased unemployment. 6,8 Increased costs, supply capacity, availability and late deliveries are some of the major challenges the industries face due to starch importation. 9 Furthermore, the importation of the starches depends on the availability of foreign currency, hence the need to explore locally grown starchy root crops as alternative raw materials. ${ }^{7}$

Cocoyam (commonly known as koko or masimbi in Malawi) produces edible starchy tubers and vegetables. The corms are used as an important source of food which can be eaten boiled, roasted or fried. Cocoyams are rich in vitamin $B_{6}$ and magnesium which help in glucose metabolization and preventing high blood pressure. ${ }^{10}$ For many years, the cocoyam plant has been used in traditional medicine. Cocoyam leaves are used as antipoisonous agents against scorpion and snake bites. In addition, the plant is used in preventing and treating cancer, anaemia, asthma, arthritis, muscle cramps and diarrhoea. ${ }^{11}$ The corm produces juice which is used to treat baldness and body ache. ${ }^{12}$ There is need therefore to evaluate the suitability of the Malawian cocoyam starch for pharmaceutical use. Utilization of these starches can economically empower local farmers, create employment opportunities and save foreign currency. The study was therefore undertaken to establish the effect of Malawian native cocoyam starch as a binder in ibuprofen tablets.

\section{MATERIALS AND METHODS}

\section{Materials}

The study used cocoyam purchased from Thekerani and Mzuzu, Malawi. Ibuprofen powder, Ac-Di-Sol, Magnesium stearate and lactose monohydrate were purchased from Sandoz South Africa (PTY) Limited, Crest Chemicals (PTY) Limited, Warren Chem Specialties (PTY) Limited and Amchem (PTY) Limited (South Africa), respectively. Only analytical and pharmaceutical grade reagents and chemicals were used.

\section{Starch extraction}

Fresh tubers were washed with tap water, peeled, washed again, chopped to about $1 \mathrm{~cm}^{3}$ cubes. The $1 \mathrm{~cm}^{3}$ cubes were mixed with water and pulverized in a high speed blender (Waring Commercial, model 8011ES) for 5 min. The pulp was suspended in $10 x$ its volume of tap water, stirred for $5 \mathrm{~min}$ and filtered using a double muslin cloth. The filtrate was allowed to stand for $2 \mathrm{~h}$ to facilitate sedimentation and the top liquid decanted as a waste. The sediment was re-suspended in 10x its volume of tap water, stirred for $5 \mathrm{~min}$ and filtered using a double muslin cloth. The filtrate was allowed to stand for $2 \mathrm{~h}$ for the starch to sediment and the top liquid decanted. The sediment was washed and air dried at room temperature for $48 \mathrm{~h}$, pulverized into fine powder and stored in polyethylene containers for further analysis. ${ }^{13}$ 


\section{Solubility of starches}

Starch suspensions $(2 \%, \mathrm{w} / \mathrm{w})$ were prepared in flasks in triplicate and heated to $50,65,75$ and $85^{\circ} \mathrm{C}$, respectively, for $30 \mathrm{~min}$ with shaking every $5 \mathrm{~min}$ and then left to cool at room temperature for $15 \mathrm{~min}$. The suspensions were centrifuged for $15 \mathrm{~min}$ at $3000 \times \mathrm{g}$ to separate gel and supernatant. The supernatant was dried in an oven for $2 \mathrm{~h}$ at $130{ }^{\circ} \mathrm{C}$ and the residue (A) obtained after drying represented the amount of starch solubilized in water. ${ }^{14}$ The solubility was calculated using equation 1 , where $S$ is the sample weight.

$$
\text { Solubility }(\%)=\frac{100 \times \mathrm{A}}{\mathrm{S}}
$$

\section{Moisture content of the starches}

In order to determine moisture content in the starch samples, the hot oven method was used. ${ }^{13,} 15$ Porcelain dishes with covers were washed and dried in an oven at $105{ }^{\circ} \mathrm{C}$ overnight, cooled to room temperature in a dessicator for $1 \mathrm{~h}$, then weighed to the nearest $1 \mathrm{mg}$. Starch samples ( $3 \mathrm{~g})$ in triplicates, were weighed in preheated, cooled and pre-weighed porcelain dishes to the nearest $1 \mathrm{mg}$. The dishes containing the samples were dried for $24 \mathrm{~h}$ at $105^{\circ} \mathrm{C}$, cooled in a dessicator for $1 \mathrm{~h}$ and immediately weighed after removal from dessicator to the nearest $1 \mathrm{mg}$. The moisture content was determined using equation 2 :

$$
\text { Moisture }(\%)=100-\left[100 \times \frac{\left(\mathrm{W}_{2}-\mathrm{W}_{0}\right)}{\left(\mathrm{W}_{1}-\mathrm{W}_{\mathrm{o}}\right)}\right]
$$

\section{pH of starches}

Starch samples ( $5 \mathrm{~g}$ ) in triplicates, were weighed into a beaker and mixed with $20 \mathrm{~mL}$ of distilled water. The resulting suspension was stirred for $5 \mathrm{~min}$ with a magnetic stirrer and left to settle for $10 \mathrm{~min}$. The $\mathrm{pH}$ of the water phase was measured using an 827 calibrated $\mathrm{pH}$ meter (Metrohn, Switzerland), which were calibrated using $\mathrm{pH} 4$ and 7 buffers. ${ }^{13}$

\section{Ash content of the starches}

Ashing crucibles were carefully cleaned and heated for 3 $\mathrm{h}$ in a furnace at $575{ }^{\circ} \mathrm{C}$. The crucibles were cooled to room temperature in a desiccator for $1 \mathrm{~h}$ and weighed to the nearest $0.1 \mathrm{mg}$. Approximately $1.0 \mathrm{~g}$ of the starch samples, to the nearest $0.03 \mathrm{mg}$ was weighed in the preweighed crucibles. The crucibles with the samples were placed in a furnace at $300^{\circ} \mathrm{C}$ overnight; removed from the furnace, cooled in a desiccator for $1 \mathrm{~h}$ at room temperature and immediately weighed after removal from desiccators. ${ }^{13}$ The ash content was calculated using equation 3:

Ash content $(\%)=100 \times \frac{\left(w_{2}-W_{0}\right)}{\left(w_{1}-W_{0}\right)}$

Formulation and compression of tablets
Batches (320 g) of basic formulations comprising ibuprofen, Ac-Di-Sol, magnesium stearate, starch and lactose were prepared. Accurately weighed amount of ibuprofen, lactose and Ac-Di-Sol were dry-mixed for 10 min in a mixer (Model T2C, willy A. Bachofen Maschinenfabrik, Switzerland). The mixture was moistened with appropriate amounts of starch mucilage to achieve various concentrations $(2,4,6$ and $8 \% \mathrm{w} / \mathrm{w})$ of the starch binders. The wet masses were granulated manually by passing them through a 10 - mesh sieve, dried in a hot-air oven for $3 \mathrm{~h}$ at $50{ }^{\circ} \mathrm{C}$, and re-sieved through a 20- mesh sieve. The obtained granules, magnesium stearate and Ac Di-Sol were measured and mixed for 10 min in a mixer. The resultant granules were stored in airtight containers for 2 days at room temperature. The granules were compressed into $400 \mathrm{mg}$ tablets at compression pressure forces ranging from 23-27 $\mathrm{Pa}$ using a Cadmach single punch (Type $\mathrm{SSF}_{3}$ Ahmedabad-India) tabletting machine and the produced tablets were stored in airtight bottles for $24 \mathrm{~h}$ at room temperature. ${ }^{16,17}$

\section{Bulk and tapped densities of the granules}

Granules (20 g), in duplicate, were weighed into a $50 \mathrm{~mL}$ measuring cylinder. The volume occupied by the granules was recorded as bulk volume. The cylinder was then tapped on the wooden platform height of $2.5 \mathrm{~cm}$ three times at 2 seconds intervals until the volume occupied by the granules remained constant. The data generated was used in computing the Hausner ratio (equation 4) and compressibility index (equation 5).

$$
\begin{aligned}
& \text { Hausner ratio }=\frac{\rho_{\mathrm{t}}}{\rho_{\mathrm{b}}} \\
& \text { Compressibility Index }=\left[\rho_{\mathrm{t}}-\frac{\rho_{\mathrm{b}}}{\rho_{\mathrm{t}}}\right] \times 100
\end{aligned}
$$

where $\rho_{b}$ is the bulk density $\left(\mathrm{g} / \mathrm{cm}^{3}\right)$ and $\rho_{t}$ is the tapped density $\left(\mathrm{g} / \mathrm{cm}^{3}\right)$

\section{Weight and thickness of tablets}

Twenty tablets from each batch were randomly selected and weighed individually using an electronic balance. Ten tablets from each batch were also selected at random and the thickness of the tablets was measured accurately to $0.01 \mathrm{~mm}$ using a digital caliper (Mitutoyo, England). ${ }^{16,18}$

\section{Friability of tablets}

Twenty tablets were selected at random, put in a 10mesh sieve, dedusted and weighed together using the electronic balance in duplicate and placed in the friabulator (Pharmatest, USA) for $4 \mathrm{~min}$ at $120 \mathrm{rev} / \mathrm{min}$. The tablets were dedusted again and reweighed. ${ }^{16,18}$ The percentage losses were calculated for each batch of the tablets using equation 6 :

$$
\text { Friability }(\%)=100 \times \frac{W_{o}-W_{f}}{W_{o}}
$$




\section{Disintegration of the tablets}

The disintegration times of the tablets were determined in distilled water at $37^{\circ} \mathrm{C} \pm 0.5^{\circ} \mathrm{C}$ using the disintegration testing apparatus (Erweka ZT500). Six tablets were selected at random from each batch placed in a cylindrical tube basket and supported on the wire mesh just above the surface of the water and the apparatus was started. The tablets were kept in contact with distilled water in the tube and the time taken for all the tablets to disintegrate and go through the wire mesh was recorded. ${ }^{17,} 19$ The disintegration efficiency (DER, a measure of tablet quality) and disintegration parameter $\left(D E R_{c}\right)$ were also determined. ${ }^{20}$

$$
\begin{aligned}
& D E R=\frac{\left(C_{s} / F_{t}\right)}{D_{t}} \\
& D E R_{c}=\frac{D E R_{\text {test }}}{D E R_{\text {ref }}}
\end{aligned}
$$

Where $C_{s}=$ crushing strength, $F_{t}=$ friability and $D_{t}=$ disintegration time

\section{Hardness of the tablets}

Ten tablets were selected at random from each batch in duplicate and a hardness tester (Pharma test PTB 301) was used. The tablet was placed between spindle and anvil of the tester and the calibrated length adjusted to zero. The knob was screwed to apply a diametric compression force on the tablet and the position on the calibrated length at which the tablet broke was recorded. ${ }^{16}$

\section{Statistical analysis of data}

Analysis of variance (ANOVA) was performed using the Genstat Discovery $13^{\text {th }}$ edition to establish the effect of cocoyam starches as binders in ibuprofen tablets. The statistically significant differences among means were tested at $95 \%$ confidence interval.

\section{RESULTS AND DISCUSSION}

The moisture and ash contents, $\mathrm{pH}$ and solubility results of the starches are presented in Table 1. The moisture content for the starches ranged from 9.36-14.00\%; and these values fall within the recommended range of less than $15 \% .{ }^{19}$ The ash content for the starches varied from $0.29-0.36 \%$ and these values are within the required maximum of $0.6 \% .{ }^{19}$ The obtained results are higher than those reported by Mweta; $0.14 \%$ was obtained for cocoyam. ${ }^{15}$ The $\mathrm{pH}$ values of the starches ranged from 4.35-5.85. The present results are lower than those reported by Mweta in which a high $\mathrm{pH}$ value of 6.4 was obtained from cocoyam. ${ }^{15}$ Solubility of all the starches in water increased as the temperature was raised from 50 ${ }^{\circ} \mathrm{C}$ to $85^{\circ} \mathrm{C}$ and differed at all temperatures ( $p \leq 0.05$ ).

The bulk and tapped densities, Hausner ratio and Carr's compressibility of the starch based ibuprofen granules are presented in Table 2. The results indicated that the bulk and tapped densities were low indicating that the granules were not porous and are poor flowing. The low densities are due to void spaces created by larger powder particles. The flow ability of the granules decreased with increasing binder concentration for all the binders except Mzuzu cocoyam $(6 \% \mathrm{w} / \mathrm{w})$. This means there was increased bonding and cohesiveness between particles leading to reduction in the flow of granules. ${ }^{21}$ Granules prepared using Mzuzu cocoyam (6 and $8 \% \mathrm{w} / \mathrm{w}$ ) and Thekerani cocoyam ( $6 \% \mathrm{w} / \mathrm{w}$ ) exhibited fair and passable flow properties; the Carr's compressibility and Hausner ratio were below $25 \%$ and 1.34 respectively. All the formed ibuprofen tablets gave acceptable uniformity of weight; no tablet afforded greater than $5 \%$ deviation in weight. The weights of the tablets varied from 388 to 418 $\mathrm{mg}$. The differences in weight variation were probably due to segregation of larger granules from the fines or non-uniform flow rate. ${ }^{22}$

The friability of the cocoyam based ibuprofen tablets are provided in Table 3 . The results revealed that friability decreased with increasing pressure for Mzuzu cocoyam (at 6 and $8 \% \mathrm{w} / \mathrm{w}$ ) and Thekerani cocoyam (at 4, 6 and 8 $\% w / w)$. Friability value of less than $1 \%$ is the required specification. ${ }^{19,23}$ The compression pressures of 26 and $27 \mathrm{~Pa}$ produced tablets which gave friability values of more than $1 \%$ for all the starch varieties at all the concentrations except Mzuzu cocoyam (2, 6 and $8 \% \mathrm{w} / \mathrm{w})$ and Thekerani cocoyam (6 and $8 \%$ w/w). The compression pressure of $24 \mathrm{~Pa}$ gave less than $1 \%$ values for all the starch formulations and thus, the tablets had good mechanical strength to withstand pressure or stress during handling, packaging and transportation. As a result, the best compression pressure was $24 \mathrm{~Pa}$ because it produced tablets which were less friable.

Table 1: Functional properties of the native starches

\begin{tabular}{|c|c|c|c|c|c|c|c|c|}
\hline $\begin{array}{c}\text { Botanical } \\
\text { source }\end{array}$ & Genotype & \multicolumn{9}{|c|}{ Functional property } \\
\hline & & $\begin{array}{c}\text { Moisture } \\
\text { content (\%) }\end{array}$ & $\begin{array}{c}\text { Ash } \\
\text { content (\%) }\end{array}$ & $\mathbf{p H}$ & \multicolumn{4}{|c|}{ Solubility (\%) } \\
\hline Cocoyam & Thekerani & $11.88 \pm 0.67$ & $0.36 \pm 0.01$ & 4.67 & $0.15 \pm 0.04$ & $1.58 \pm 0.08$ & $8.73 \pm 2.62$ & $15.69 \pm 0.41$ \\
\hline & Mzuzu & $14.00 \pm 0.02$ & $0.31 \pm 0.02$ & 5.40 & $0.36 \pm 0.05$ & $1.63 \pm 0.07$ & $5.69 \pm 0.05$ & $10.85 \pm 0.28$ \\
\hline Corn & Corn & $9.36 \pm 0.30$ & $0.29 \pm 0.03$ & 4.35 & $0.23 \pm 0.04$ & $1.69 \pm 0.37$ & $4.85 \pm 0.81$ & $8.84 \pm 2.14$ \\
\hline
\end{tabular}


Table 2: Granule properties of starch based ibuprofen

\begin{tabular}{|c|c|c|c|c|c|c|c|c|c|c|c|c|c|c|c|c|}
\hline \multirow{2}{*}{$\begin{array}{c}\text { Binder conc. }(\% \mathrm{w} / \mathrm{w}) \\
\text { Genotype }\end{array}$} & \multicolumn{4}{|c|}{2} & \multicolumn{4}{|c|}{4} & \multicolumn{4}{|c|}{6} & \multicolumn{4}{|c|}{8} \\
\hline & $\begin{array}{l}\text { Bulked } \\
\text { density }\end{array}$ & $\begin{array}{l}\text { Tapped } \\
\text { density }\end{array}$ & $\begin{array}{l}\text { Hausner } \\
\text { ratio }\end{array}$ & $\begin{array}{l}\text { Carr's } \\
\text { index }\end{array}$ & $\begin{array}{l}\text { Bulked } \\
\text { density }\end{array}$ & $\begin{array}{l}\text { Tapped } \\
\text { density }\end{array}$ & $\begin{array}{l}\text { Hausner } \\
\text { ratio }\end{array}$ & $\begin{array}{l}\text { Carr's } \\
\text { index }\end{array}$ & $\begin{array}{l}\text { Bulked } \\
\text { density }\end{array}$ & $\begin{array}{l}\text { Tapped } \\
\text { density }\end{array}$ & $\begin{array}{c}\text { Hausner } \\
\text { ratio }\end{array}$ & $\begin{array}{l}\text { Carr's } \\
\text { index }\end{array}$ & $\begin{array}{l}\text { Bulked } \\
\text { density }\end{array}$ & $\begin{array}{l}\text { Tapped } \\
\text { density }\end{array}$ & $\begin{array}{c}\text { Hausner } \\
\text { ratio }\end{array}$ & $\begin{array}{l}\text { Carr's } \\
\text { index }\end{array}$ \\
\hline Thekerani & 0.49 & 0.62 & 1.25 & 19.76 & 0.49 & 0.65 & 1.32 & 24.39 & 0.50 & 0.62 & 1.23 & 18.75 & 0.47 & 0.62 & 1.32 & 24.42 \\
\hline Mzuzu & 0.48 & 0.66 & 1.37 & 27.12 & 0.48 & 0.66 & 1.38 & 27.38 & 0.49 & 0.62 & 1.26 & 20.73 & 0.48 & 0.60 & 1.25 & 20.24 \\
\hline
\end{tabular}

Table 3: Friability of ibuprofen tablets

\begin{tabular}{|c|c|c|c|c|c|c|c|c|c|c|c|c|c|c|c|c|c|c|c|c|}
\hline \multirow{2}{*}{$\begin{array}{c}\text { Conc. (w/w) } \\
\text { Setting }\end{array}$} & \multicolumn{5}{|c|}{2} & \multicolumn{5}{|c|}{4} & \multicolumn{5}{|c|}{6} & \multicolumn{5}{|c|}{8} \\
\hline & 23 & 24 & 25 & 26 & 27 & 23 & 24 & 25 & 26 & 27 & 23 & 24 & 25 & 26 & 27 & 23 & 24 & 25 & 26 & 27 \\
\hline Mzuzu & $\begin{array}{c}0.31 \\
\pm \\
0.04\end{array}$ & $\begin{array}{c}0.40 \\
\pm \\
0.04\end{array}$ & $\begin{array}{c}0.39 \\
\pm \\
0.02\end{array}$ & $\begin{array}{c}0.39 \\
\pm \\
0.02\end{array}$ & $\begin{array}{c}2.19 \\
\pm \\
0.03\end{array}$ & $\begin{array}{c}0.31 \\
\pm \\
0.01\end{array}$ & $\begin{array}{c}0.47 \\
\pm \\
0.06\end{array}$ & $\begin{array}{c}1.19 \\
\pm \\
0.09\end{array}$ & $\begin{array}{c}4.81 \\
\pm \\
0.04\end{array}$ & $\begin{array}{c}4.95 \\
\pm \\
0.09\end{array}$ & $\begin{array}{c}0.34 \\
\pm \\
0.02\end{array}$ & $\begin{array}{c}0.23 \\
\pm \\
0.02\end{array}$ & $\begin{array}{c}0.40 \\
\pm \\
0.01\end{array}$ & $\begin{array}{c}0.49 \\
\pm \\
0.02\end{array}$ & $\begin{array}{c}3.81 \\
\pm \\
0.06\end{array}$ & $\begin{array}{c}0.72 \\
\pm \\
0.03\end{array}$ & $\begin{array}{c}0.35 \\
\pm \\
0.01\end{array}$ & $\begin{array}{c}0.41 \\
\pm \\
0.03\end{array}$ & $\begin{array}{c}0.45 \\
\pm \\
0.06\end{array}$ & $\begin{array}{c}4.99 \\
\pm \\
0.01\end{array}$ \\
\hline Thekerani & $\begin{array}{c}0.28 \\
\pm \\
0.02\end{array}$ & $\begin{array}{c}0.46 \\
\pm \\
0.06\end{array}$ & $\begin{array}{c}0.42 \\
\pm \\
0.01\end{array}$ & $\begin{array}{c}3.74 \\
\pm \\
0.11\end{array}$ & $\begin{array}{c}4.92 \\
\pm \\
0.01\end{array}$ & $\begin{array}{c}0.48 \\
\pm \\
0.01\end{array}$ & $\begin{array}{c}0.42 \\
\pm \\
0.02\end{array}$ & $\begin{array}{c}0.44 \\
\pm \\
0.06\end{array}$ & $\begin{array}{c}3.61 \\
\pm \\
0.22\end{array}$ & $\begin{array}{c}4.14 \\
\pm \\
0.06\end{array}$ & $\begin{array}{c}0.39 \\
\pm \\
0.01\end{array}$ & $\begin{array}{c}0.38 \\
\pm \\
0.02\end{array}$ & $\begin{array}{c}0.43 \\
\pm \\
0.09\end{array}$ & $\begin{array}{c}0.52 \\
\pm \\
0.02\end{array}$ & $\begin{array}{c}4.97 \\
\pm \\
0.01\end{array}$ & $\begin{array}{c}10.5 \\
1 \pm \\
0.67\end{array}$ & $\begin{array}{c}0.36 \\
\pm \\
0.01\end{array}$ & $\begin{array}{c}0.39 \\
\pm \\
0.04\end{array}$ & $\begin{array}{c}0.42 \\
\pm \\
0.01\end{array}$ & $\begin{array}{c}3.92 \\
\pm \\
0.06\end{array}$ \\
\hline
\end{tabular}

The disintegration results of cocoyam starch based ibuprofen tablets are provided in Figure 1. The results show that all the tablets disintegrated within $15 \mathrm{~min}$, the recommended maximum for the British pharmacopoeia for uncoated tablets. ${ }^{19} \mathrm{Mzuzu}$ cocoyam based ibuprofen tablets disintegrated in less than $10 \mathrm{~min}$. The disintegration time increased with increasing pressure (23-25 Pa) and then decreased at higher pressure (26-27 Pa). Increasing compaction pressure either increases or decreases disintegration time. ${ }^{24}$ At a pressure of $23 \mathrm{~Pa}$, Thekerani cocoyam starch produced soft

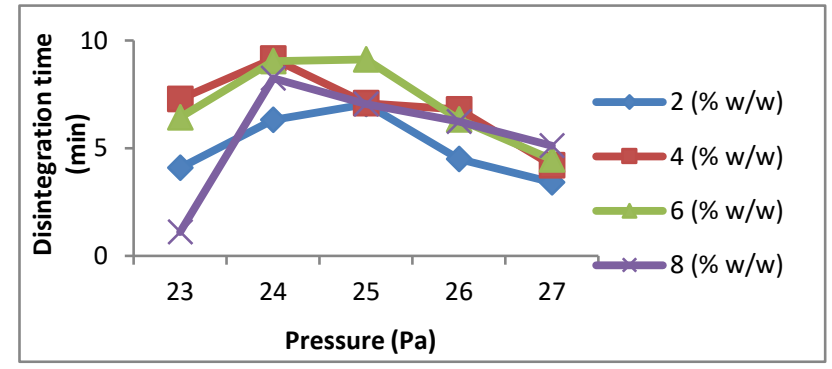

(a) Mzuzu cocoyam tablets which disintegrated in less than $1 \mathrm{~min}$ at $8 \% \mathrm{w} / \mathrm{w}$ binder concentrations. The swelling mechanism induced disintegration easily probably due to ineffective binding between the particles. The $2 \% \mathrm{w} / \mathrm{w}$ ibuprofen tablets disintegrated within $7 \mathrm{~min}$ at all the compression pressures and starch varieties. The results are understandable because a good disintegrant must be effective at low concentrations. ${ }^{25}$ Eraga and coresearchers reported that the cocoyam tablets which they produced disintegrated within 7 min. ${ }^{26}$

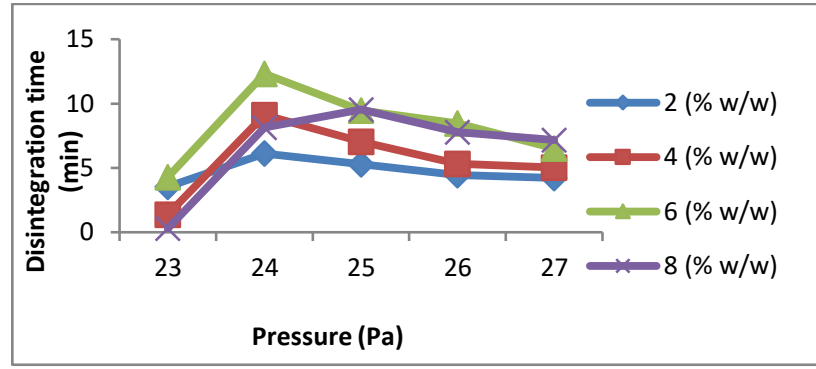

(b) Thekerani cocoyam

Figure 1: Effect of pressure and concentration on the disintegration time of cocoyam starch based ibuprofen tablets 
The hardness of cocoyam starch based ibuprofen tablets are presented in Figure 2. The hardness increased with an increase in binder concentration and compression pressure (23-25 $\mathrm{Pa}$ ) for all formulations. The increase in hardness was due to strong bridges and tablet binding mechanism leading to greater association. High binder concentrations cause an increase in plastic deformation

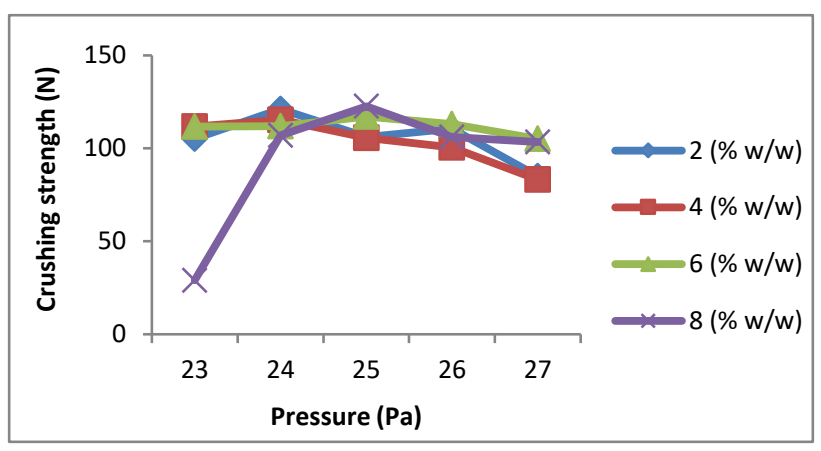

(a) Mzuzu cocoyam of the formulation, and formulation of more solid bonds which in return result in an increase in tablet strength. ${ }^{17}$, 27 The minimum requirement for hardness is $4 \mathrm{~kg}$ or $\geq 60$ N. ${ }^{19,28}$ Using a compression pressure of $23 \mathrm{~Pa}$, Thekerani cocoyam (4, 6 and $8 \% \mathrm{w} / \mathrm{w}$ ) and Mzuzu cocoyam (8\% $\mathrm{w} / \mathrm{w}$ ) failed to comply with the specifications.

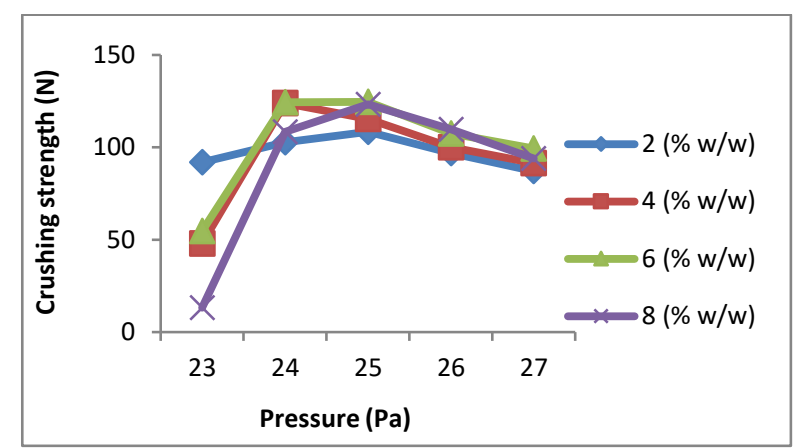

(b) Thekerani cocoyam

Figure 2: Effect of pressure and concentration on the hardness of cocoyam starch based ibuprofen table

Table 4: Hardness-disintegration ratio and disintegration efficiency ratio of ibuprofen tablets

\begin{tabular}{|c|c|c|c|c|c|c|c|}
\hline Cultivar & $\begin{array}{c}\text { Binder conc. (\% } \\
w / w)\end{array}$ & Hardness (N) & Friability (\%) & $\begin{array}{l}\text { Disintegration } \\
\text { time (min) }\end{array}$ & HDR & DER & DER $_{\mathrm{c}}$ \\
\hline \multirow[t]{4}{*}{ Thekerani } & 2 & 102.70 & 0.46 & 6.12 & 16.78 & 36.48 & 0.47 \\
\hline & 4 & 123.90 & 0.42 & 9.11 & 13.60 & 32.38 & 0.42 \\
\hline & 6 & 124.50 & 0.38 & 9.44 & 13.19 & 34.71 & 0.45 \\
\hline & 8 & 107.00 & 0.36 & 8.15 & 13.13 & 36.47 & 0.47 \\
\hline \multirow[t]{4}{*}{ Mzuzu } & 2 & 121.10 & 0.40 & 6.31 & 19.19 & 47.98 & 0.62 \\
\hline & 4 & 115.40 & 0.47 & 9.17 & 12.58 & 26.78 & 0.35 \\
\hline & 6 & 111.90 & 0.23 & 9.05 & 12.36 & 53.76 & 0.70 \\
\hline & 8 & 107.00 & 0.35 & 8.25 & 12.97 & 47.06 & 0.61 \\
\hline Corn & & 104.50 & 0.18 & 7.55 & 13.90 & 76.89 & \\
\hline
\end{tabular}

Table 4 shows a comparison of the produced tablets at the punch setting of 24 with corn starch based ibuprofen tablets. The hardness of the tablet batches were within the acceptable range of $\geq 60 \mathrm{~N}$ and it was observed that the hardness increased with increasing binder concentration for most starches except Mzuzu cocoyam starch which decreased with increasing binder concentration. Thekerani ( 2 and $8 \% \mathrm{w} / \mathrm{w}$ ) and Mzuzu cocoyam (6 and $8 \% \mathrm{w} / \mathrm{w}$ ) starches produced tablets which were comparable in hardness to the corn starch ( $p$ $\geq 0.05$ ). It was found that increasing the binder concentration caused either a corresponding increase or decrease in friability of the tablets. The obtained friability values were less than $0.5 \%$ for all the formulations.

The hardness-friability ratio (HFR) provides a parameter for measuring tablet strength. ${ }^{29}$ The higher the HFR value, the stronger the tablet is. ${ }^{17}$ However, the disintegration efficiency ratio (DER) can also measure the hardness and disintegration properties of tablets. ${ }^{30}$ Tablets with good balance between disintegration and binding properties have higher DER values. ${ }^{31}$ Corn based tablets have high DER value than cocoyam tablets. This means that the tablets which contained cocoyam starches had low balance between disintegration and mechanical properties. However, the disintegration times of the produced tablets at $2 \% \mathrm{w} / \mathrm{w}$ were less than the reference tablets. This confirms that the best binder concentration is $2 \% \mathrm{w} / \mathrm{w}$.

\section{CONCLUSION}

The study has shown the potential of cocoyam as a binder in tablet formation. Cocoyam starches can be used as binders in ibuprofen tablets; compression pressure of 24 $\mathrm{Pa}$ and binder concentration of $2 \% \mathrm{w} / \mathrm{w}$. Under such conditions, less friable tablets are produced and reduced amounts of materials are used. Mzuzu cocoyam starch is the most appropriate binders for ibuprofen tablets. 


\section{REFERENCES}

1. Chibuzor, A. B., Augusta, U., Josephat, O., Chukwemeka, M., Oguchukwu, U. and Sabinus, O., Effects of chemical modification of Manihot esculenta starch on the Phyisco-Chemical, Binder and Disintegrant Properties of Metronidazole Tablet Formulation, Acta Scientific Pharmaceutical Sciences, 3(3), 2019, 66-76.

2. Awunor, D.O., Isimi, C.Y., Oguegbulu, J.C. and Lori, J.A., Evaluation of Crude Yam Starch from white Yam (Dioscorea rotundata poir.) as a Pharmaceutical Excipient in Tableting of Paracetamol, Australian Journal of Basic and Applied Sciences, 13(6), 2019, 32-38.

3. Iyagba, A.G., A review on root and tuber crop production and their weed management among small scale farmers in Nigeria, Asian Research Publishing Network Journal of Agricultural and Biological Sciences, 5(4), 2010, 52-58.

4. Choroenthai, N. Sanga-ngam, T. and Puttipipatkhachorn, S., Use of modified Taopica Starches as Pharmaceutical excipients, Pharmaceutical Sciences Asia, 45(4), 2018, 195-204.

5. Chitedze, J., Monjerezi M., Kalenga, J.D. and Steenkamp, J., Binding Effect of Cassava Starches on the Compression and Mechanical Properties of Ibuprofen Tablets, Journal of Applied Pharmaceutical Science, 02 (04), 2012, 31-37.

6. Masumbu, F.F.F., Production of Cold-setting Adhesives Using Starch and Dextrins from Cassava (Manihot esculenta Crantz) [dissertation]. University of Malawi, 2002.

7. National Statistical Office, Bill of Entry on Starches, Dextrins and Other Modified Starches (2005-2010), Zomba, Malawi, 2010.

8. National Statistical Office, Bill of Entry on Starches, Dextrins and Other Modified Starches (1994-1999), Zomba, Malawi, 1999.

9. Itaye, S., Opportunities of using cassava starch in the packaging industry. A paper presented at the policy framework workshop for cassava. Cresta Hotel, Lilongwe, 27-28th May, 2008.

10. Olatidoye, O.P., Adenoye, D.A. and Idemudia, B. J., Influence of Chemical Modification on Some Properties of Starches from Tiger Nut (Cyperus esculenta) and Cocoyam (Xanthosoma sagittifolium) as a Potential Biomaterial, International Research Journal of Biological Sciences, 1 (1), 2019, 13-24.

11. Kalariya, M., Parmar, S. and Sheth, N, Neuropharmacological Activity of Hydro Alcoholic Extract of Leaves of Colocasia esculenta. Pharm Bio, 48 (11): 2010, 1207-1212.

12. Kusuma, R., Reddy, V.P. and Rao A.S.S., Evaluation of Colocasia esculenta Starch as An Alternative Tablet Excipient to Maize Starch: Assessment by Performulation and Formulation studies. International Journal of Pharma Sciences and Research, 6, 2015, 5765.

13. Benesi, I.R.M., Native Starch Evaluation and Analysis of Genetic Distance Using AFLP of Elite Cassava (Manihot esulenta Crantz) Genotypes from Malawi [dissertation]. University of Free State, South Africa, 2002, 52-54.

14. Odeku, O.A. and Picker-Freyer, K.M., Analysis of the Material and Tablet Formation Properties of Four Dioscorea Starches, Starch/Stärke, 59: 2007, 430-444.

15. Mweta, D.E., Physicochemical, Functional and Structural Properties of Native Malawian Cocoyam and Sweetpotato Starches [dissertation]. University of Free State, South Africa, 2009, 73-74.
16. Ibezim, E.C., Emeje, M.O., Ofoefule, S.I., Onyishi V.I. and Odoh, U.E., The Role of Ginger Starch As a Binder in Acetaminophen Tablets, Scientific Research and Essay, 3(2), 2008, 46-50.

17. Adetunji, O.A., Odeniyi, M.A. and Itiola, O.A., Compression, Mechanical and Release Properties of Chloroquine Phosphate Tablets Containing Corn and Trifoliate Yam Starches as Binders, Tropical Journal of Pharmaceutical Research, 5(2), 2006, 589-596.

18. Patil, B.S., Rao, K.D., Kulkarni, U., Khalid, M.S. and Korwar, P.G., Properties of Zingiber officinale Starch as a Novel Tablet Binder, International Journal of Pharmaceutical Sciences, 2(3), 2010, 717 723.

19. British Pharmacopoeia, Vol. I, II, III and IV University Press Cambridge, 2009.

20. Adjei, F.K., Osei, Y.A., Kunkworbe, N.F. and Ofori-Kwakye, K. (2017). Evaluation of the Disintegrant Properties of Native Starches of Five New Cassava Varieties in Paracetamol Tablet Formulations. Hindawi, Journal of Pharmaceutics: 2017, 2017, 1-9.

21. Abdulsamad, A., Isah, A.B., Bathia, P.G. and Kenneth, A., Comparative Evaluation of Tablet Binding Properties of Cashew (Anacardium occidentale L.) Gum in Metronidazole Tablet Formulation, Best Journal, 15 (2), 2008, 140-145.

22. Allagh, T.S., Ibrahim, Y.K.E. and Ojile, J.E., Drug Distribution in Granules: Effect of Diluents and Granule Size on the Distribution of a Low Hydrophilic Low Dose Drug in Granules. Nigerian Journal of Pharmaceutical Sciences, 7(1), 2008, 32-40.

23. Ansel, H.C., Popovich N. G. and Allen L. V., Tablets. In: Ansel's Pharmaceutical Dosage Forms and Drug Delivery Systems, $9^{\text {th }}$ edition, Philadelphia: Wolters Kluwer Health: Lippincott Williams and Wilkins, 2011, 225-243.

24. Aulton, M.E., Tablets and Compaction. In: Aulton's Pharmaceutics: The Design and Manufacture of Medicines, $3^{\text {rd }}$ edition, Oxford: Churchill Livingstone Elsevier, 2007, 442-478.

25. Ramu, G., Mohan K. G., Jayaveera, K.N., Suresh, N., Prakash, K. C. and Ramesh B. (2010). Evaluation of Abelmoschus Starch as Tablet Disintegrant. Indian Journal of Natural a product and Resources, 1(3): 342-347.

26. Eraga, S.O, Meko, O. A. and Iwuagwu, M.A., Evaluation of Xerosels of Cassava and Cocoyam Starches as Dry Granulation Binders and Disintegrants in Directly Compressed Paracetamol Tablets Formulations, Pharmaceutical and Biomedical Research, 4(4), 2018, 19-24.

27. Musa, H., Muazu, J. and Bhatia, P.G., Evaluation of Fonio (Digitaria exilis) Starch as a Binder in Paracetamol Tablets, Nigerian Journal of Pharmaceutical Sciences, 7 (1), 2008, 56-66.

28. Cirunay, J.J.N. and Vercammen, J.A.P., Evaluation of Xylitab 200, a New Filler/Binder for Direct Compression, Using Factorial Design. Drug Development and Industrial Pharmacy, 23 (4), 1997, 363-368.

29. Odeku, O.A. and Itiola, O.A., Evaluation of the Effects of Khaya Gum on the Mechanical and Release Properties of Paracetamol Tablet Formulation. Drug Development India Pharm, 2003; 23: 311-320.

30. Asseng, S., Cammarano, D., Basso, B., Chung, U., Alderman, P.D., Sonder, K., Reynolds, M. and Lobell, D.B., Hot Spots of Wheat Yield Decline with Rising Temperatures. Global Change Biology, 23 (6): 2017, 2464-2472.

31. Upadrashta, S.M., Katikaneni, P.R. and Nuessle, N.O., Chitosan as a Tablet Binder, Drug Development and Industrial Pharmacy, 18 (15), 1992, 1701-170.

\section{Source of Support: None declared.}

Conflict of Interest: None declared.

For any question relates to this article, please reach us at: editor@globalresearchonline.net

New manuscripts for publication can be submitted at: submit@globalresearchonline.net and submit_ijpsrr@rediffmail.com 